\title{
Differential $B C C I P$ gene expression in primary human ovarian cancer, renal cell carcinoma and colorectal cancer tissues
}

\author{
XIAOXIA LIU ${ }^{1 *}$, LINGLING CAO $^{2 *}$, JINSONG NI $^{3}$, NING LIU $^{1}$, XIAOMING ZHAO ${ }^{2}$, YANFANG WANG $^{3}$, \\ LIN ZHU $^{2}$, LINGYAO WANG ${ }^{2}$, JIN WANG $^{4}$, YING YUE ${ }^{1}$, YONG CAI $^{2,5}$ and JINGJI JIN ${ }^{2,5}$ \\ ${ }^{1}$ Department of Gynecologic Oncology, The First Clinical Hospital of Jilin University, Changchun, Jilin 130021; \\ ${ }^{2}$ School of Life Sciences, Jilin University, Changchun, Jilin 130012; Departments of ${ }^{3}$ Pathology and ${ }^{4}$ Urology, \\ The First Clinical Hospital of Jilin University, Changchun, Jilin 130021; ${ }^{5}$ National Engineering Laboratory \\ for AIDS Vaccine, School of Life Sciences, Jilin University, Changchun, Jilin 130012, P.R. China
}

Received July 26, 2013; Accepted September 18, 2013

DOI: $10.3892 /$ ijo.2013.2124

\begin{abstract}
Human BCCIP, a protein which interacts with BRCA2 and CDKN1A (Cip1, p21), has been implicated in many cellular processes including cell cycle regulation, DNA recombination and damage repair, telomere maintenance, embryonic development and genomic stability. BCCIP gene expression, which is an important BRCA2 cofactor in tumor suppression, has been identified in some primary cancers. Thus, we investigated the role of BCCIP expression in a large sample of clinically diagnosed primary ovarian cancer, renal cell carcinoma (RCC) and colorectal cancer (CRC) tissues. Using clinically diagnosed frozen primary cancer tissues, quantitative PCR (qPCR), western blot analysis (WB) and immunohistochemical staining (IHC) approaches were used to detect and measure gene expression. Reduced BCCIP gene expression in ovarian cancer, RCC and CRC tissues occurred in 74,89 and $75 \%$ of tissue samples, respectively. qPCR analysis of mRNA expression in 54 ovarian cancer, 50 RCC
\end{abstract}

Correspondence to: Professor Ying Yue, Department of Gynecologic Oncology, The First Clinical Hospital of Jilin University, 71 Xinmin Street, Changchun, Jilin 130021, P.R. China

E-mail: yying119@126.com

Professor Jingji Jin, School of Life Sciences, Jilin University, 2699 Qianjin Street, Changchun, Jilin 130012, P.R. China

E-mail: jjjin@jlu.edu.cn

*Contributed equally

Abbreviations: $\mathrm{BCCIP}, \mathrm{BRCA} 2$ and $\mathrm{CDKN} 1 \mathrm{~A}$ interacting protein; $\mathrm{RCC}$, renal cell carcinoma; CRC, colorectal cancer; $\mathrm{qPCR}$, quantitative real-time PCR; RT-PCR, reverse transcription polymerase chain reaction

Key words: BCCIP gene, ovarian cancer, renal cell carcinoma, colorectal cancer and 44 CRC samples revealed significant ( $>2$-fold decreased) $B C C I P$ downregulation in 56,70 and $46 \%$ of tissue samples, respectively. Although $B C C I P$ expression in three different tumor tissues decreased, the relationship between $B C C I P$ expression and clinicopathological features of each cancer was distinct. Compared to normal tissues, BCCIP expression in ovarian cancers was significantly downregulated in serous, endometrioid and mucinous carcinomas. Downregulation of $B C C I P$ expression was strongly associated with clear cell RCC (ccRCC) and Fuhrman tumor grading, but significant differences in BCCIP expression between CRC and matched normal tissues occurred only in male CRC tissues $(\mathrm{p}<0.05)$ and in tissue with a T4 tumor stage $(\mathrm{p}<0.01)$. Thus, BCCIP protein was chiefly reduced in ovarian cancer and RCC tissue samples $(\mathrm{p}<0.05)$. BCCIP gene expression was downregulated in human ovarian cancer, RCC and CRC tissues, suggesting a role for the gene in the pathogenesis of these cancers.

\section{Introduction}

The human $B C C I P$ gene has been characterized based on its interaction with BRCA 2 and $\mathrm{p} 21$ protein $(1,2)$, and its protein is an evolutionarily conserved nuclear protein with multiple interacting domains: an $\mathrm{N}$-terminus acidic domain, an internal conserved domain, and the C-terminus variable domain (2). The N-terminal half of BCCIP shares moderate homology with regions of calmodulin and $\mathrm{M}$-calpain, suggesting that BCCIP may be an important cofactor for BRCA2 in tumor suppression (2). The BCCIP gene is alternatively spliced to produce two commonly expressed isoforms, $B C C I P \alpha$ (322 aa) and $B C C I P \beta$ (314 aa) (3). Experimental evidence indicates that both $B C C I P \alpha$ and $B C C I P \beta$ can interact with $\mathrm{p} 21$ and BRCA2 (3-5). Although human cells express both isoforms, $B C C I P \beta$ expression is relatively consistent in cancer cells, whereas expression of $B C C I P \alpha$ varies among cancer cell lines (2). Research suggests that $B C C I P$ is important in many cellular processes. Overexpression of $B C C I P \beta$ delays G1-to-S cell cycle progression and elevates $\mathrm{p} 21$ expression, suggesting that BCCIP $\beta$ can regulate control of cell growth (6). In 
contrast, BCCIP protein depletion leads reduced p21 expression and impairs G1-S checkpoint activation in response to ionizing radiation in HT1080 cells. This regulation of $\mathrm{p} 21$ expression by BCCIP depends on p53 (7). Downregulation of BCCIP in HT1080 cells results in chromosomal polyploidization, centrosome amplification, and abnormal mitotic spindle formation, pointing to BCCIP for the maintenance of genomic integrity (8). BCCIP may also interact in the BRCA2- and RAD51-dependent response to DNA damage and homologous recombinational repair (HRR) $(5,9)$. Recent findings suggest that BCCIP is required for mouse embryonic development and structural stability of chromosomes (10). Collectively, this evidence illustrates a critical role for BCCIP in fundamental cellular processes.

Ovarian cancer, RCC and CRC are cancers with relatively high clinical incidence rates. Ovarian cancer is the most common cause of cancer death arising from gynecologic tumors (11). RCC is a common genitourinary malignancy, accounting for $3 \%$ of all cancers worldwide (12), and CRC is a major cause of mortality and morbidity, representing the third most common cancer in men and the second most common cancer in women worldwide (13). Due to early detection difficulties, most ovarian cancers, RCC and CRC are diagnosed at advanced stages. Various diagnostic and prognostic biomarkers of these cancers have been identified, including potential tumor hypoxic markers HIF1 $\alpha$ (hypoxia inducible factor- $1 \alpha$ ) and its regulated genes such as vascular endothelial growth factor (VEGF) and carbonate anhydrate IX (CA9) (14-16). However, these markers are not sufficiently specific or sensitive to predict accurately the survival of ovarian cancer patients $(17,18)$. The $B C C I P$ gene, an important cofactor for $B R C A 2$ in tumor suppression, is implicated in many important cellular processes with obvious links to cancer. Thus, we investigated whether BCCIP expression is lost in human tumor tissues, and if so, whether the correlation between the loss of BCCIP expression and clinicopathological features is similar in different tumor tissues. Previously, reduction in BCCIP protein have been reported in brain, breast and endometrial cancer cell lines, suggesting a potential role of BCCIP in cancer etiology (2). Although Meng et al detected BCCIP mRNA expression in a limited number of cancer tissues (15 kidney, 11 colon, 9 breast, 8 stomach, 7 rectal, 7 uterine, 3 prostate, 3 lung, 3 ovarian, 1 cervical and 1 small intestine) (3), the role of BCCIP protein and the relationship between $B C C I P$ expression and the clinicopathological features of cancers have not been reported. Here, we measured BCCIP mRNA and protein expression in multiple primary ovarian cancer, RCC and CRC cases using qPCR, WB and IHC. In addition, we analyzed the relationship between BCCIP gene expression and the clinicopathological features of these three cancer types.

\section{Materials and methods}

Antibodies and tissue collection. Anti-BCCIP (16043-1-AP) polyclonal antibody was purchased from Protech Group (Wuhan, China). Rabbit polyclonal anti-GAPDH was raised against bacterially expressed proteins (Jilin University, Changchun, China). Human clinical tumor tissues (ovarian cancer, RCC and CRC) and normal tissues were collected from patients with primary ovarian cancers between January 2010 and July 2012, from patients with primary RCC between May 2009 and May 2012, and primary CRC cases between July 2012 and March 2013. Cancer patients underwent radical tumor surgery at the First Hospital of Jilin University. The study was approved by the Ethics Committee of the First Hospital of Jilin University and all patients gave informed consent for the use of their tissue samples. Patient medical records including patient age and gender, tumor staging, pathological diagnosis and surgical records were reviewed. Tumors were staged according to the 2010 TNM classification system using the American Joint Committee on Cancer (AJCC) stage grouping (19). No patients received chemotherapy or radiotherapy before surgery.

Reverse transcription PCR (RT-PCR). Total RNA from tumor (ovarian cancer, RCC or CRC) or normal tissues were isolated using TRIzol LS Reagent (Invitrogen). Then, $1 \mu \mathrm{g}$ of total RNA from each sample was used as a template to produce cDNA with the PrimeScript 1st Strand cDNA Synthesis Kit (Takara). BCCIP and GAPDH mRNA were measured by PCR using a $\mathrm{C} 1000^{\mathrm{TM}}$ Thermal Cycler (Bio-Rad) and quantitative real-time PCR with an Eco Real-Time PCR System (Illumina). All PCR reactions were finished as follows: initial denaturation step at $95^{\circ} \mathrm{C}$ for $30 \mathrm{sec}$, followed by 40 cycles of denaturation at $95^{\circ} \mathrm{C}$ for $5 \mathrm{sec}$, annealing at $60^{\circ} \mathrm{C}$ for $30 \mathrm{sec}$ and extension at $72^{\circ} \mathrm{C}$ for $30 \mathrm{sec}$. Primer sets used for PCR were as follows: GAPDH, 5'-ATCACTGCCACCCAGA AGAC-3' (forward) and 5'-ATGAGGTCCACCACCCTGTT-3' (reverse), yielding a 460-bp product; BCCIP, 5'-TCAAGA GTTGGTTCTACGCTTC-3' (forward) and 5'-CATGGG CAGAGCGATCTGT-3' (reverse), yielding a 110-bp product.

Western blot analysis. Cancer tissue or normal tissue samples (200 mg) were homogenized with liquid nitrogen and solubilized in $200 \mu \mathrm{l}$ cold PBS containing 1.0\% Nonidet P-40, $0.5 \%$ sodium deoxycholate, $0.1 \%$ SDS, $0.05 \mathrm{mM}$ PMSF and protease inhibitor cocktail. The homogenate was swirled and kept on ice for $30 \mathrm{~min}$. Whole-cell extracts were sonicated (Scientz-IID, Zhejiang, China) for $10 \mathrm{sec}$ with 50\% duty cycle and centrifugation (13,400 x g for $30 \mathrm{~min})$. The protein concentration of the resulting supernatant was measured using the Bio-Rad Protein Assay kit (500-0201). Equal amounts of protein from tissue whole-cell lysates were mixed with $4 \mathrm{X}$ SDS-containing sample buffer and boiled for $5 \mathrm{~min}$ at $95^{\circ} \mathrm{C}$. Denatured proteins were then separated by $12 \%$ SDS-PAGE. Specific proteins were detected by WB using BCCIP and GAPDH polyclonal antibodies.

IHC staining. Formalin-fixed and paraffin-embedded ovarian cancer and CRC tissue blocks were obtained from the First Clinical Hospital of Jilin University. Tissue blocks were sectioned and deparaffinized in xylene and rehydrated through a graded ethanol series. Tissue slides were then subjected to antigen retrieval by boiling in $0.01 \mathrm{M}$ sodium citrate buffer (pH 6.0) in a microwave oven for $10 \mathrm{~min}$. Endogenous peroxidase was blocked by incubation for $10 \mathrm{~min}$ in $3 \%$ hydrogen peroxide in methanol. Finally, the reactions were detected using a DAB detection kit (Dako). Anti-BCCIP (16043-1-AP) polyclonal antibody was used at a 1:500 dilution. 
A
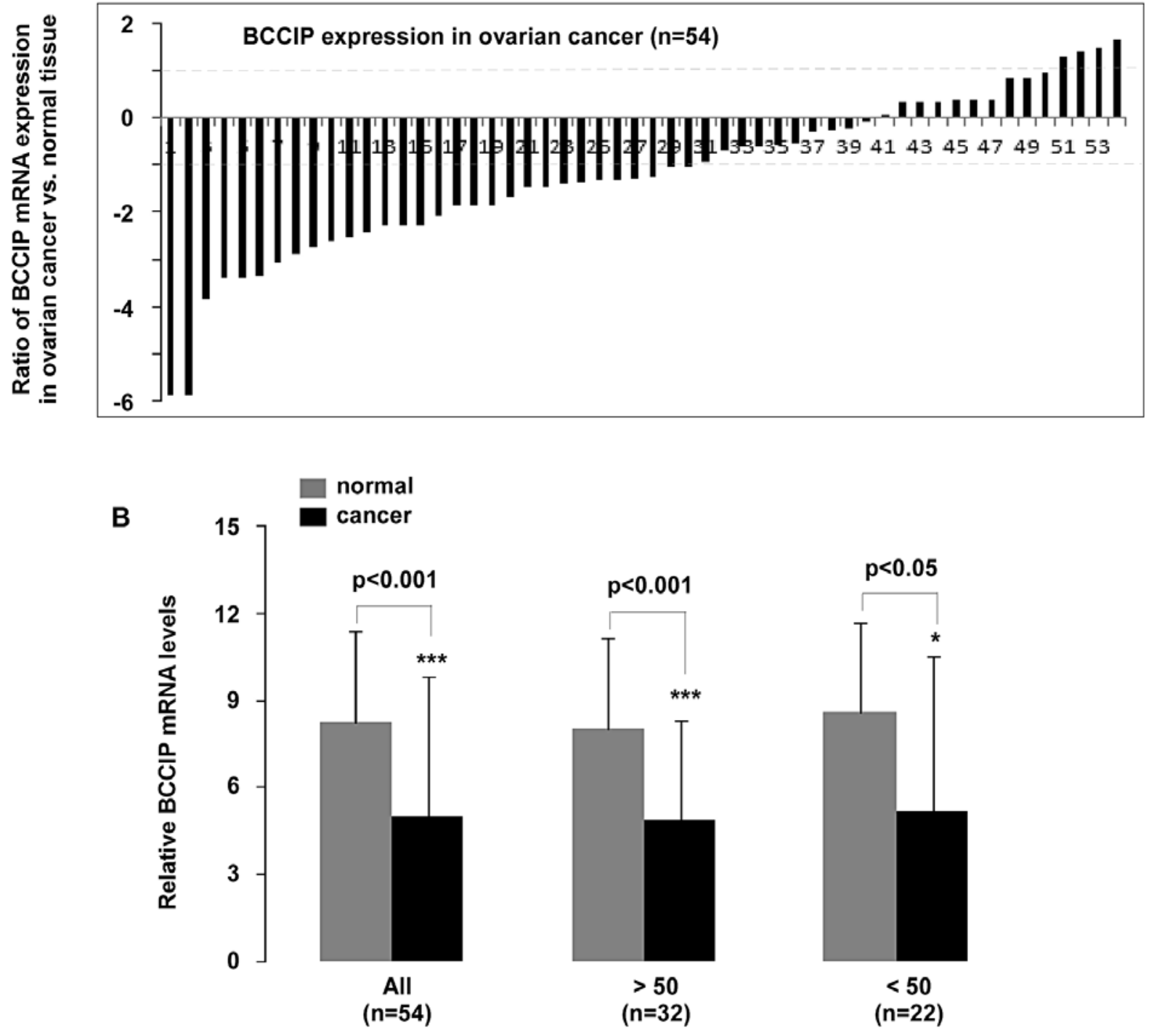

Figure 1. Downregulation of human BCCIP mRNA is observed in ovarian cancer. Total RNA was isolated from 54 clinical ovarian cancer tissues and 15 normal tissues (8/15 cases were contralateral normal tissues). Relative mRNA expression of BCCIP was analyzed by qPCR. (A) Ratio of BCCIP mRNA expression in ovarian cancer vs. normal tissues. Each bar is the $\log 2$ value of the ratio of BCCIP expression between ovarian cancer and normal tissues. A bar value $>1$ represents $>2$-fold increases, whereas a bar value $<1$, represents a $>2$-fold decrease. (B) Relationship between $B C C I P$ gene expression and tissue source age. $\geq 50$ or $<50$ represents tissues from patients aged 50 years or older or younger than 50 years, respectively. $B C C I P$ mRNA expression is depicted as an average \pm standard deviation (SD). Statistical comparisons were analyzed using the Student's t-test. Significant differences are expressed as ${ }^{*} \mathrm{p}<0.05,{ }^{* * *} \mathrm{p}<0.001$.

Statistical analysis. Differences in gene and protein expression between tumor and normal tissues were statistically analyzed using SPSS 17.0 (SPSS Inc., Chicago, IL). Statistical comparisons were analyzed using the Student's t-test. Values of $p<0.05$ were considered to be statistically significant.

\section{Results}

BCCIP expression and clinicopathological features of ovarian cancer. To understand $B C C I P$ expression in the pathogenesis of primary ovarian cancer, we measured BCCIP mRNA using qPCR in 54 patients diagnosed with ovarian cancer. Patients aged $>50$ years accounted for 32 cases, and the remaining 22 cases were $<50$. Statistical analysis of qPCR data revealed that BCCIP expression was significantly decreased in ovarian cancer compared to normal tissues ( $\mathrm{p}<0.001, \mathrm{n}=54)$. Moreover, BCCIP expression in patients $>50$ or $<50$ years was reduced $(\mathrm{p}<0.001$ and $\mathrm{p}<0.05$, respectively) (Fig. 1B). As shown in Fig. 1A, mRNA expression in the 54 samples was significantly downregulated ( $>2$-fold decrease) in $56 \%$ (30/54) of tissue samples, whereas $7 \%(4 / 54)$ of samples had significantly upregulated ( $>2$-fold increase) BCCIP. In addition, a $<2$-fold reduction in $B C C I P$ expression was observed in $19 \%(10 / 54)$ of the ovarian cancer tissue samples.

Cell subtypes were assigned according to refined World Health Organization (WHO) criteria (20) as recently described (21). A significant ( $>2$-fold decrease) downregulation of BCCIP mRNA in 56\% (20/36) of serous carcinoma samples, in $55 \%(6 / 11)$ of endometrioid carcinoma samples $(n=11)$ and in $75 \%(3 / 4)$ of mucinous carcinoma samples $(n=4)$ was 
A

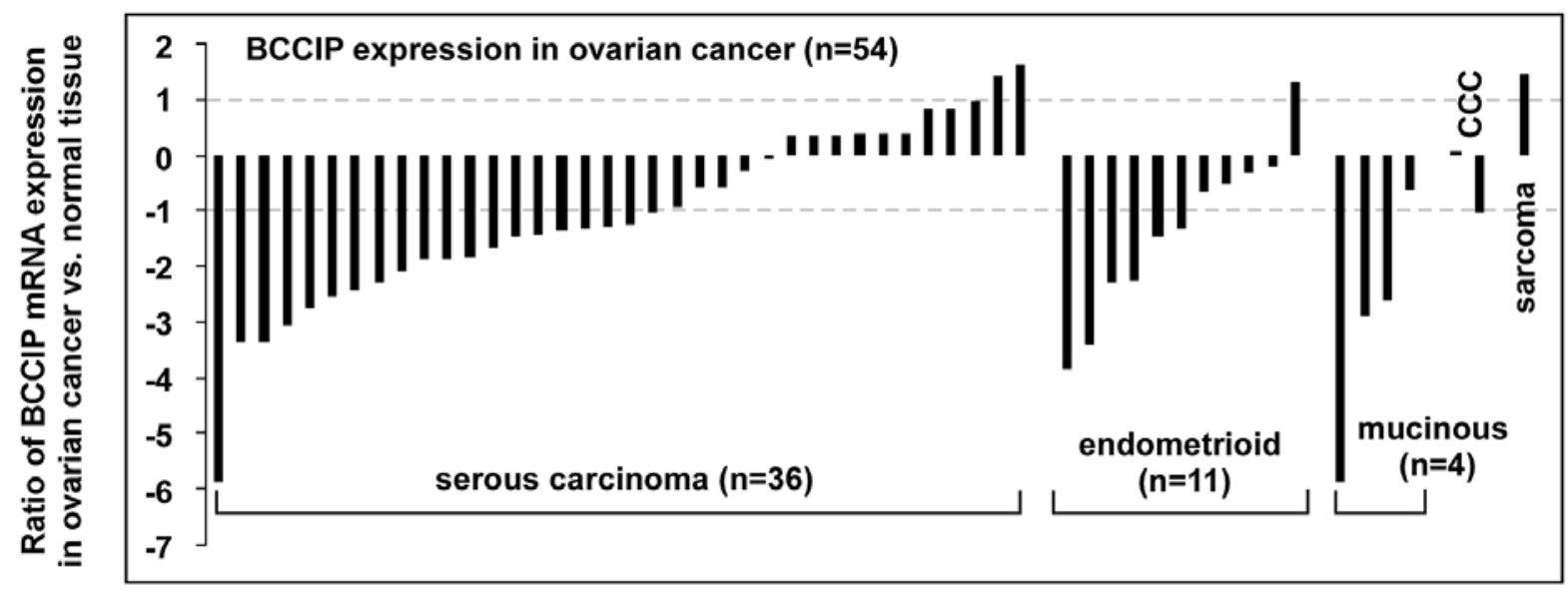

B

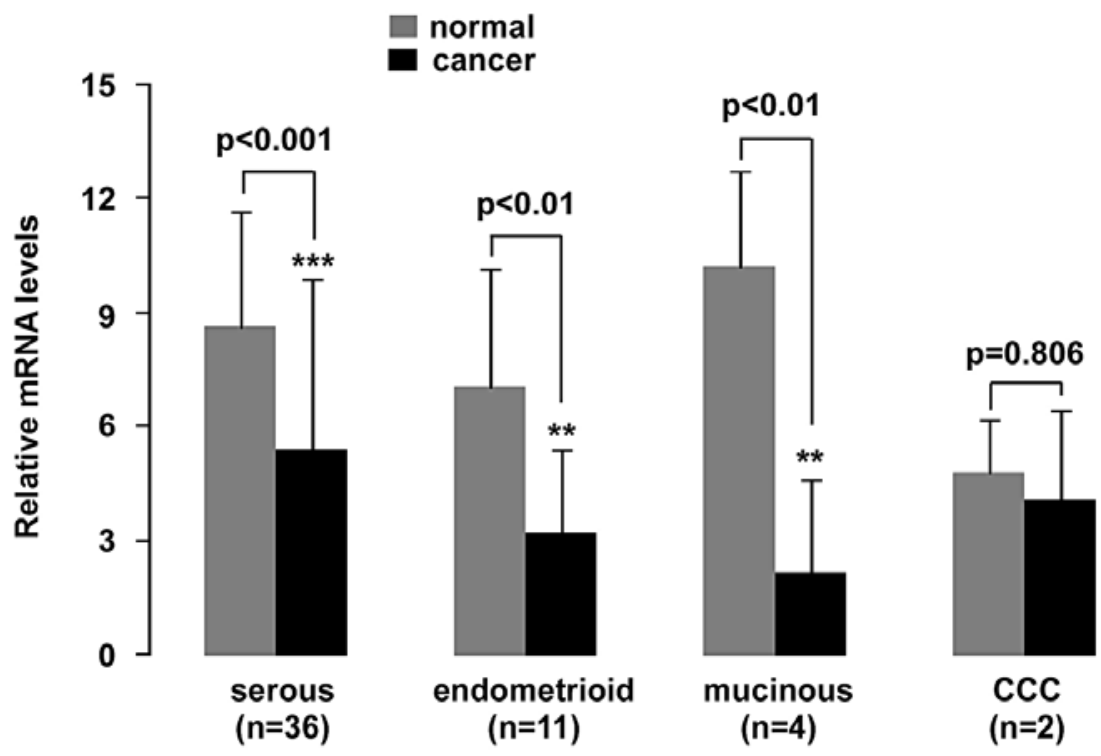

Figure 2. Relationship between $B C C I P$ expression and pathological diagnosis of ovarian cancer. (A) Ratio of $B C C I P$ mRNA expression in different pathological diagnosed ovarian cancer including serous carcinoma $(n=36)$, endometrioid carcinoma $(n=11)$, mucinous carcinoma $(n=4)$, clear cell carcinoma $(n=2)$ and sarcoma $(n=1)$ vs. normal tissues. (B) qPCR data for different types of ovarian cancer tissues are indicated as a bar graph. Each bar represents average \pm SD.

Table I. Relationship between BCCIP expression and pathological diagnosis of ovarian cancer.

\begin{tabular}{|c|c|c|c|c|c|}
\hline \multirow{2}{*}{$\begin{array}{l}\text { Pathological } \\
\text { diagnosis }\end{array}$} & \multirow{2}{*}{$\begin{array}{l}\text { Average } \\
\text { age }\end{array}$} & \multirow{2}{*}{$\begin{array}{l}\text { No. of } \\
\text { cases (n) }\end{array}$} & \multicolumn{2}{|c|}{$\begin{array}{c}\text { BCCIP mRNA (qPCR) } \\
\text { (average } \pm \text { SD) }\end{array}$} & \multirow{2}{*}{$\begin{array}{c}\text { P-value } \\
\text { (normal vs. cancer) }\end{array}$} \\
\hline & & & Normal & Cancer & \\
\hline Serous carcinoma & 50 & 36 & $8.59 \pm 3.03$ & $5.39 \pm 4.48$ & $0.00083^{\mathrm{a}}$ \\
\hline pT1 stage & 49.3 & 6 & $10.2 \pm 3.43$ & $5.31 \pm 3.42$ & $0.0482^{\mathrm{b}}$ \\
\hline pT2 stage & 50.5 & 22 & $7.57 \pm 2.91$ & $5.55 \pm 5.17$ & 0.127 \\
\hline pT3 stage & 49.5 & 8 & $10.2 \pm 1.35$ & $5.05 \pm 2.81$ & $0.000611^{\mathrm{a}}$ \\
\hline Endometrioid carcinoma & 42.5 & 11 & $7.05 \pm 3.09$ & $3.19 \pm 2.18$ & $0.00425^{\mathrm{c}}$ \\
\hline pT1 stage & 48.8 & 5 & $8.98 \pm 2.33$ & $4.69 \pm 2.15$ & $0.0268^{\mathrm{b}}$ \\
\hline pT2 stage & 37.3 & 6 & $5.45 \pm 2.72$ & $1.94 \pm 1.22$ & $0.0249^{\mathrm{b}}$ \\
\hline
\end{tabular}

The significant difference is expressed as ${ }^{\mathrm{a}} \mathrm{p}<0.001,{ }^{\mathrm{b}} \mathrm{p}<0.05$ and ${ }^{\mathrm{c}} \mathrm{p}<0.01$. 
A
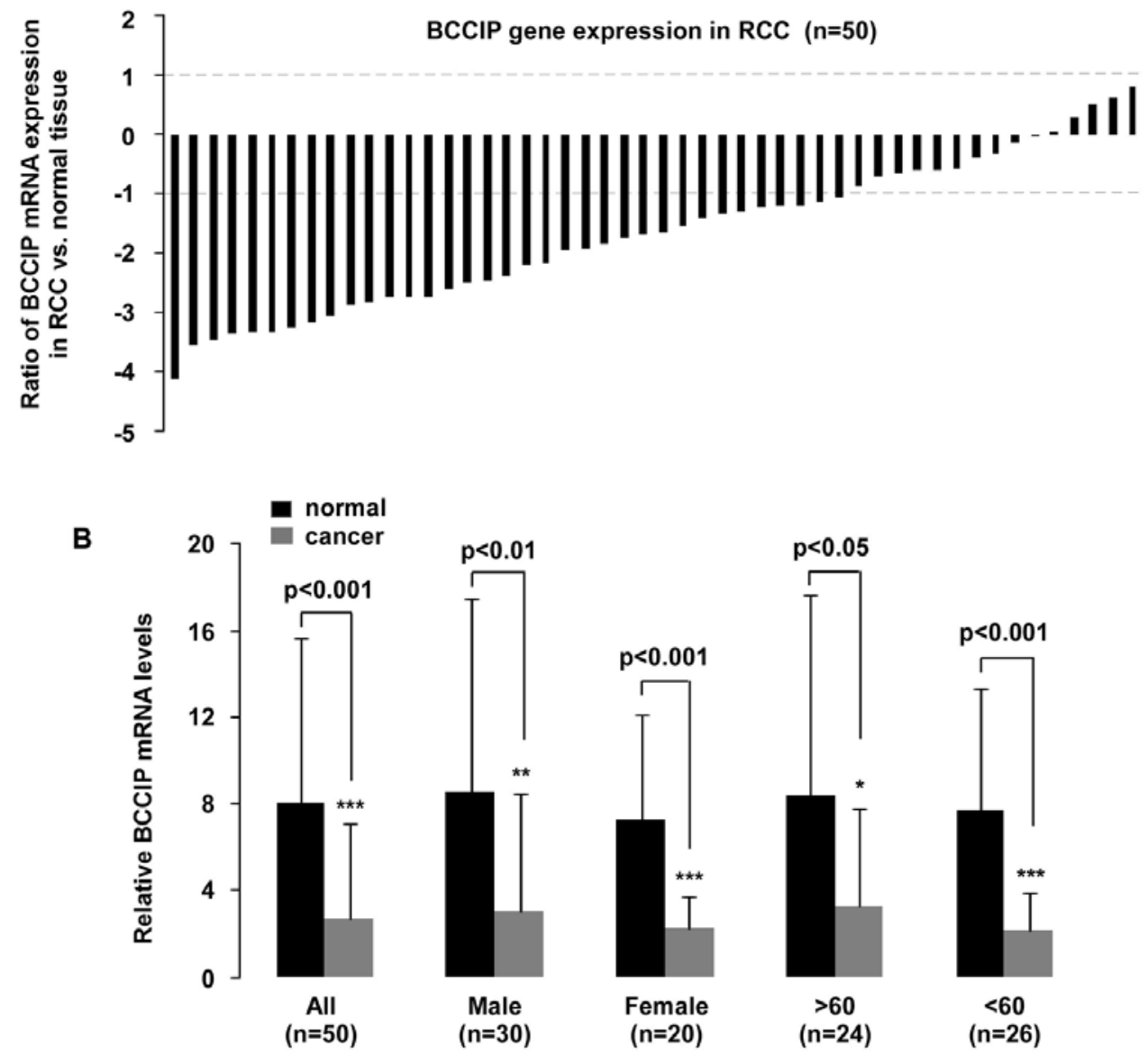

Figure 3. Frequent downregulation of $B C C I P$ mRNA is verified in human RCC. Cases $(\mathrm{n}=50)$ of clinically diagnosed RCC tissues and matched normal tissues were used in this experiment. (A) BCCIP mRNA is frequently downregulated in RCC tissues. Isolated ( $1 \mu \mathrm{g})$ total RNA from RCC and matched normal tissues was produced cDNA and the relative mRNA expression of $B C C I P$ were analyzed by qPCR. Each bar represents the $\log 2$ value of the ratio of $B C C I P$ expression between RCC and normal tissues. (B) Statistical analysis of the relationship between BCCIP expression and the age or gender. Each bar represents an average \pm SD.

observed $(\mathrm{p}<0.001, \mathrm{p}<0.01$ and $\mathrm{p}<0.01$, respectively). Over 2-fold elevation of $B C C I P$ was detected in only one sarcoma case (Fig. 2).

Next, BCCIP expression and tumor stage were correlated (Table I). Significantly low expression of BCCIP was observed in pT1- and pT3-stage serous tumors $(\mathrm{p}<0.05$ and $\mathrm{p}<0.001$, respectively), and in pT1- and pT2-stage endometrioid carcinomas ( $\mathrm{p}<0.05$ and $\mathrm{p}<0.05$, respectively). However, BCCIP downregulation was not observed in the $\mathrm{T} 2$ stage of serous carcinoma $(\mathrm{p}=0.127)$.

BCCIP expression in ccRCC and Fuhrman grading. BCCIP expression was measured in 50 samples. Histological subtypes were classified as clear cell RCC (ccRCC), papillary RCC (paRCC), chromophobe RCC (chRCC) and unclassified RCC (unRCC) according to previous WHO classifications (22). qPCR revealed that BCCIP gene expression was downregulated in $\mathrm{RCC}(\mathrm{p}<0.001, \mathrm{n}=50$; Fig. 3B). A significant $(>2$-fold decreased) reduction of BCCIP expression was detectable in $70 \%(35 / 50)$ of the RCC samples, and a $<2$-fold reduction of BCCIP mRNA was observed in 18\% (9/50) of the RCC samples. Although BCCIP expression was upregulated in $10 \%(5 / 50)$ of samples, the fold-change of all RCC samples was less than 2-fold. In addition, one sample was not different with respect to BCCIP expression, compared to normal tissues (Fig. 3A).

BCCIP expression and tissue age/gender was investigated (Fig. 3B). A statistically significant reduction of BCCIP expression was observed in tissues from males $(n=30, p<0.01)$, females $(n=20, p<0.001)$, in tissue from persons $>60$ years of age $(n=24, p<0.05)$ and $<60$ years $(n=26, p<0.001)$, compared with normal tissues. Furthermore, mRNA expression in the 50 RCC samples was compared to the histological tumor type and Fuhrman grading. Downregulation of BCCIP expression in RCC was strongly associated with ccRCC $(\mathrm{p}<0.001)$, but no significant difference was observed in paRCC $(\mathrm{p}=0.468)$ and chRCC $(p=0.228)$, compared with normal tissues (Fig. 4A). Fuhrman nuclear grading is the most widely used and most predictive grading system for RCC, and this scale was used to assess the nuclear grade in each RCC sample (23). The correlation between BCCIP expression and tumor Fuhrman grading is shown in Fig. 4B. Low BCCIP expression in RCC was strongly associated with Fuhrman grading. A significant reduction ( $>2$-fold decrease) of BCCIP mRNA occurred in $68 \%(21 / 31)$ of Fuhrman grade II samples and in $77 \%(10 / 13)$ of Fuhrman grade III samples $(p<0.05$ and $\mathrm{p}<0.01$, respectively). 
A
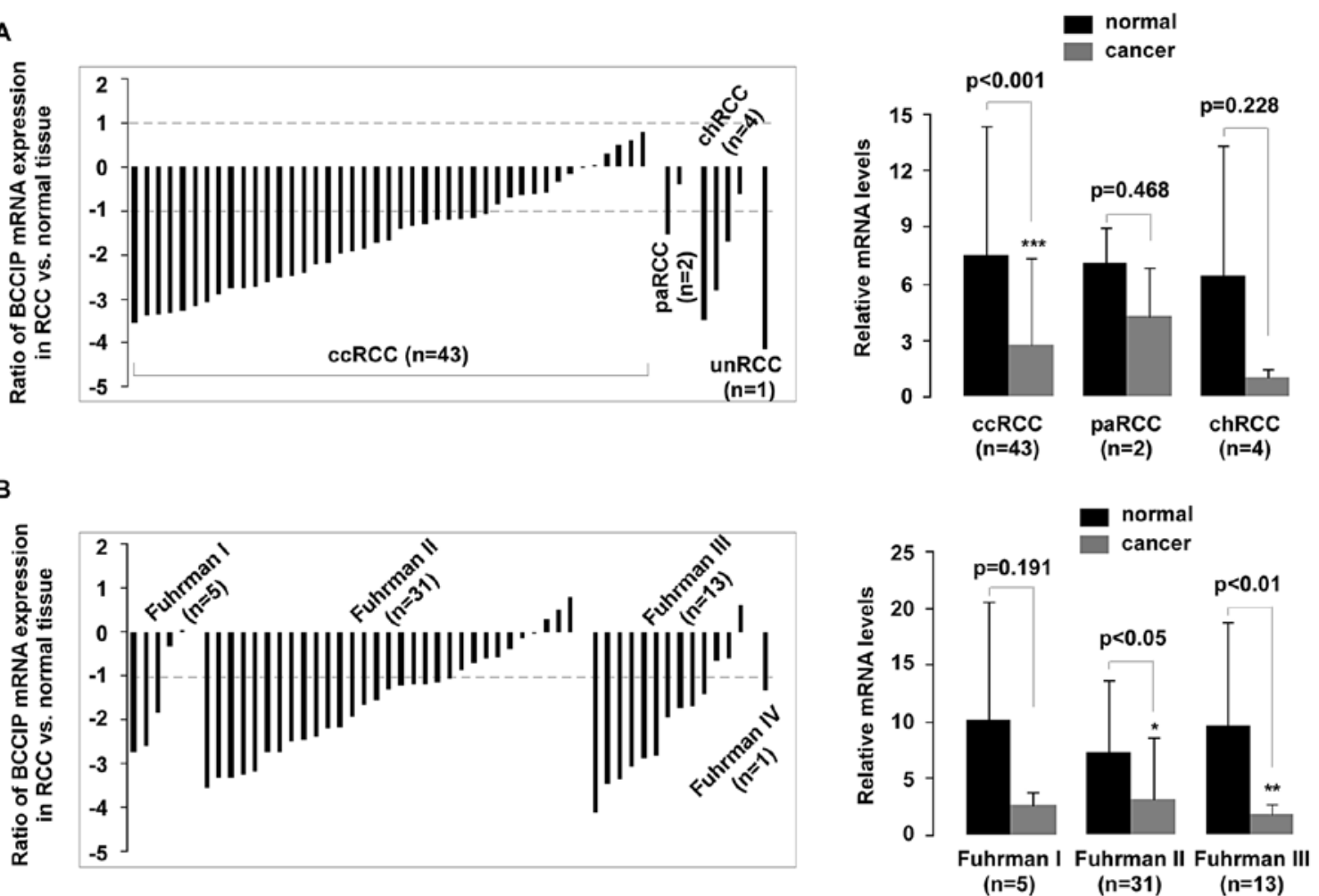

Figure 4. Correlation between BCCIP expression and clinicopathological features in RCC. (A) qPCR data were analyzed according to clinical diagnostic tumor types. Left panel represents the $\log 2$ value of the ratio of $B C C I P$ expression between RCC and normal tissues. The right panel depicts relative $B C C I P$ mRNA. (B) Relationship between BCCIP expression and Fuhrman grades of RCC. Left panel represents the log2 value of the ratio of BCCIP expression between RCC and normal tissues. Right panel depicts relative BCCIP mRNA. Each bar represents average \pm SD.

A

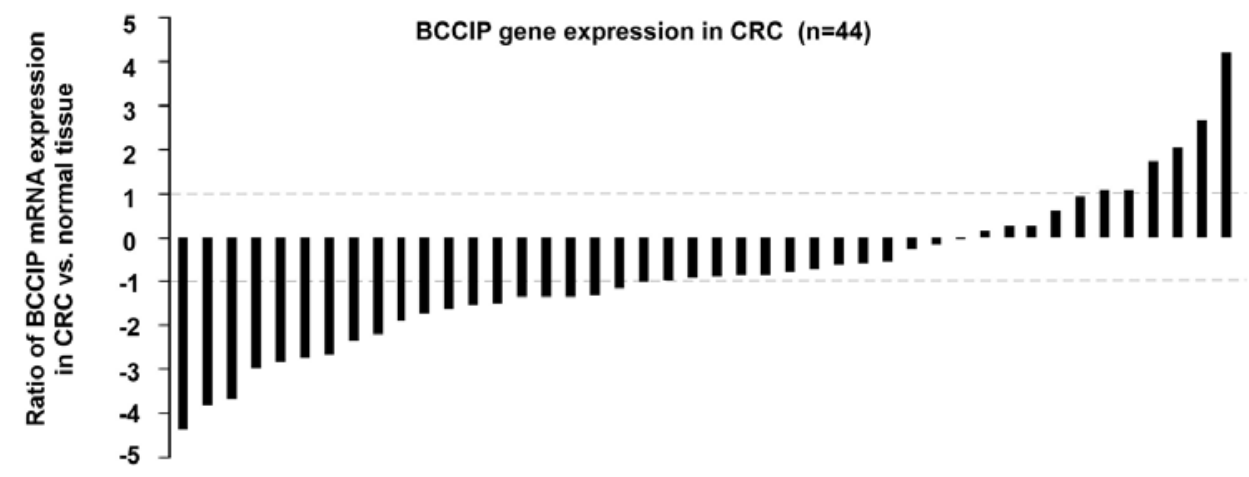

B

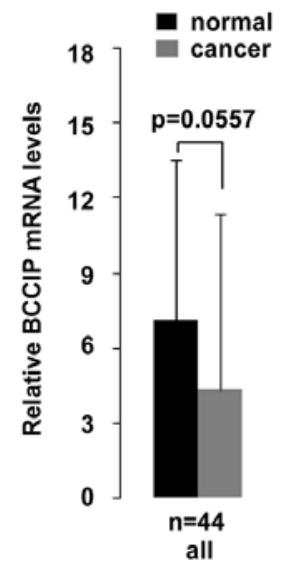

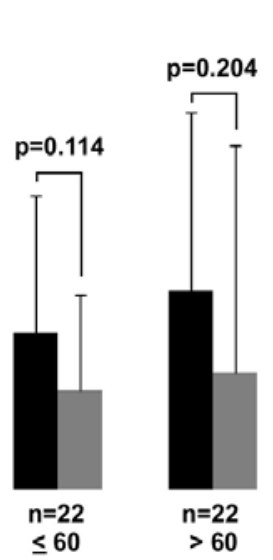

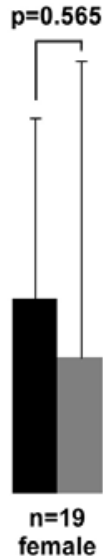

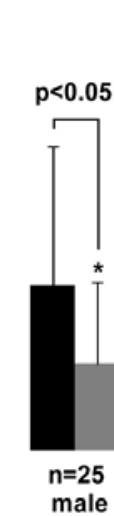

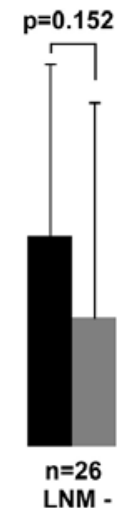

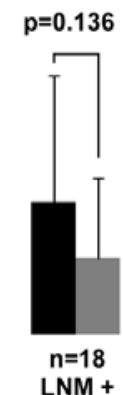

Figure 5. Statistical analysis of BCCIP expression and age, gender and lymph node metastasis of patients with CRC. Total RNA was isolated from 44 CRC tissues and matched normal tissues. Relative mRNA expression of BCCIP was measured by qPCR. (A) BCCIP mRNA expression patterns in CRC tissues. The $\mathrm{y}$-axis indicates the $\log 2$ value of the ratio of BCCIP expression between CRC and normal tissues from the same patients. (B) Relationship between BCCIP gene expression and age, gender and lymph node metastasis of CRC tissues. Each bar represents the average \pm SD. 
A

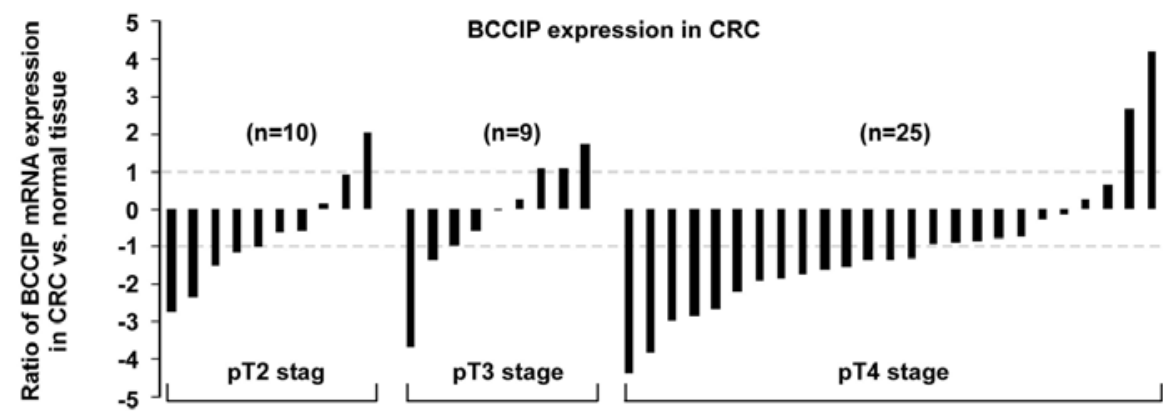

B

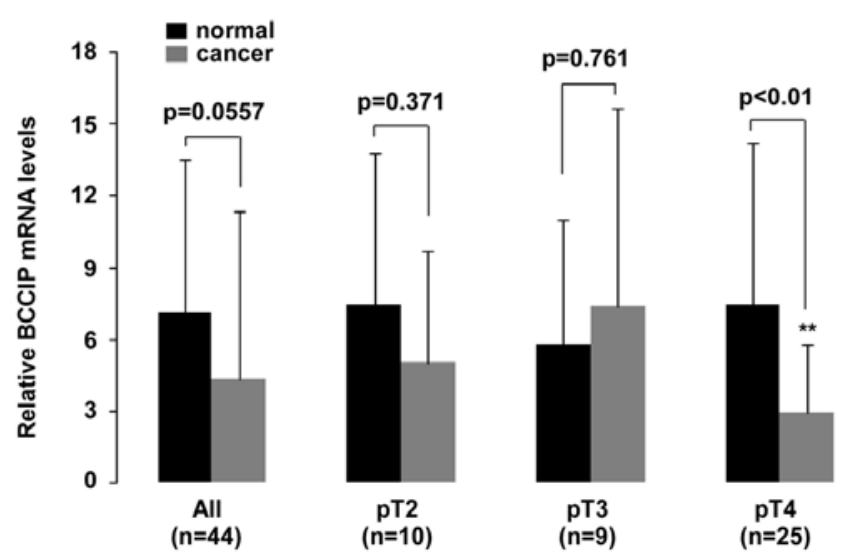

Figure 6. Relationship between BCCIP expression and pathological grades of CRC. qPCR data were analyzed according to pathological grades of CRC. (A) Log2 value of the ratio of BCCIP expression between CRC and matched normal tissues. (B) Statistical analysis of qPCR results. Each bar represents the average \pm SD.

BCCIP expression in male and pT4 CRC tumors. Compared with the previous tumor tissues studied BCCIP expression in CRC is not as remarkable. When compared with age- and gender-matched normal tissues, BCCIP expression in CRC tissues decreased, but this was not statistically significant $(\mathrm{p}=0.0577)$ between cancer and normal tissues (Fig. 5B). A $>2$-fold reduction of BCCIP expression was observed in $45 \%$ (20/44) of CRC tissues, and a $<2$-fold reduction of BCCIP mRNA was observed in $29 \%$ (13/44) of tissues. In contrast, a $>2$-fold elevation of BCCIP expression was detectable in $14 \%(6 / 44)$ of tissues, whereas a $<2$-fold overexpression of BCCIP mRNA was present in $11 \%$ (5/44) of tissues (Fig. 5A). As shown in Fig. 5B, BCCIP expression in tissues from male patients with $C R C$ was significantly decreased $(p<0.05)$, but no statistically significant difference existed between tumor and normal tissues in other CRC tissue groups compared. After analysis for TNM tumor stage (Fig. 6), a significant reduction of BCCIP mRNA was only observed in pT4 CRC tumors $(\mathrm{p}<0.01)$.

$B C C I P$ protein in ovarian cancer, $R C C$ and $C R C$. To investigate reduction of $B C C I P$ expression and potentially decreased BCCIP protein, we randomly selected samples from ovarian cancer tissue $(n=12)$, RCC tissue $(n=10)$ and CRC tissue $(n=12)$ and compared these to normal tissues (Fig. 7). As shown in the upper panel, aliquots of whole-cell extract from all tissues were analyzed by WB using indicated antibodies. Quantified protein was analyzed with the Student's t-test (Quantity One software). As shown in Fig. 7B, BCCIP protein expression was significantly decreased in ovarian cancer and RCC tissues compared with their matched normal tissues $(\mathrm{p}=0.0404$ and $\mathrm{p}=0.0421$, respectively). Although BCCIP protein in CRC tissues decreased, this was not statistically significant. To confirm this observation, we performed IHC for BCCIP in formalin-fixed paraffin-embedded tissue sections from 20 ovarian cancer tissues and 34 CRC tissues. Data show that BCCIP protein was reduced (score $0-1$ for BCCIP) in $70 \%(14 / 20)$ of ovarian cancer samples and in 35\% (12/34) of CRC samples. IHC staining for BCCIP in ovarian cancer and CRC is shown in Fig. 8. Negative (middle) or positive (bottom) staining of BCCIP in ovarian carcinoma and CRC paraffin-embedded tissue sections are depicted.

\section{Discussion}

The human BCCIP gene, located at 10q26 (1) has been implicated in many cellular processes such as cell cycle regulation, DNA recombination, DNA repair, telomere maintenance, embryonic development and genomic stability (6-10). These data strongly suggest a role for BCCIP in tumor development and progression. BCCIP has been implicated in several forms of human tumors such as astrocytic brain tumors $(24,25)$. Here, we report data regarding differential BCCIP gene expression in tumor tissues including ovarian cancer $(n=54)$, RCC $(n=50)$ and CRC $(n=44)$ by qPCR. BCCIP protein was measured using WB and IHC staining. Statistical analysis of experimental results revealed a significant reduction of BCCIP expression in ovarian cancer $(\mathrm{p}<0.001)$ and RCC tissues 
A

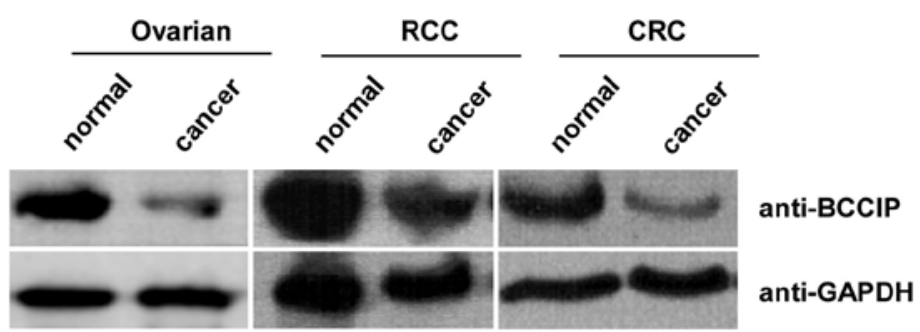

B

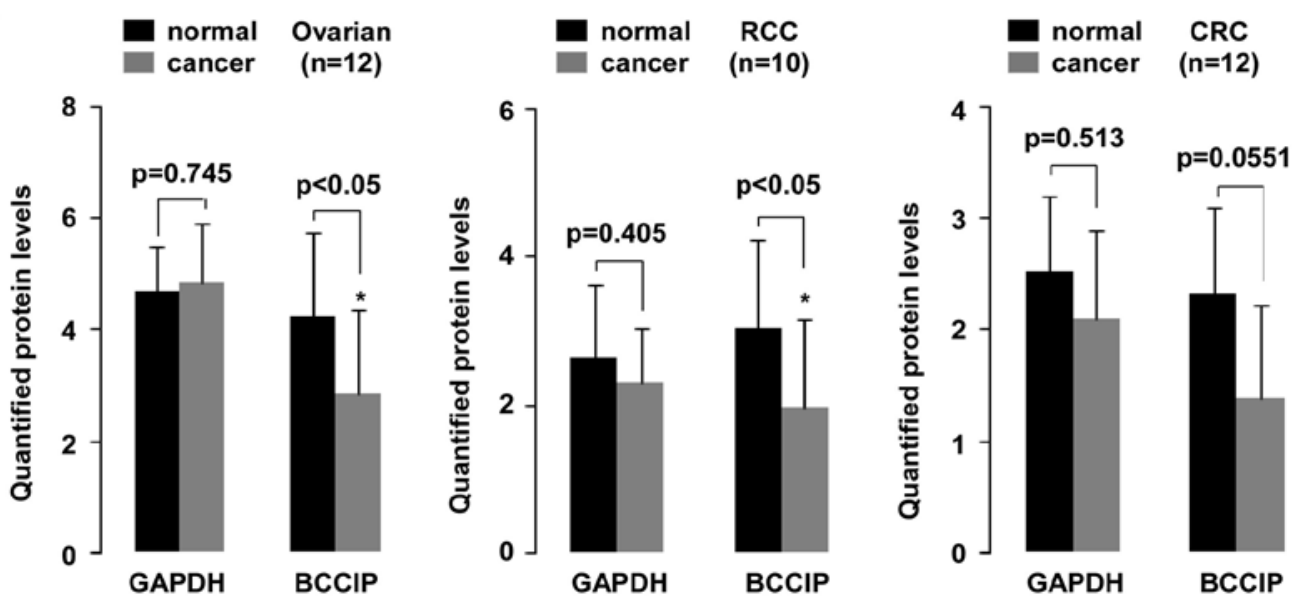

Figure 7. Reduction of BCCIP protein in primary ovarian cancer tissues and RCC, but not in CRC tissues. (A) Aliquots of whole cell extracts from selected ovarian cancer $(n=12), \operatorname{RCC}(n=10)$ and CRC ( $n=12)$ samples and normal tissues were subjected to SDS-PAGE (12\% gels), and proteins were detected by western blot analysis with the indicated antibodies. (B) Relative BCCIP protein. Western blot images were scanned and quantified using Quantity One software (Bio-Rad).

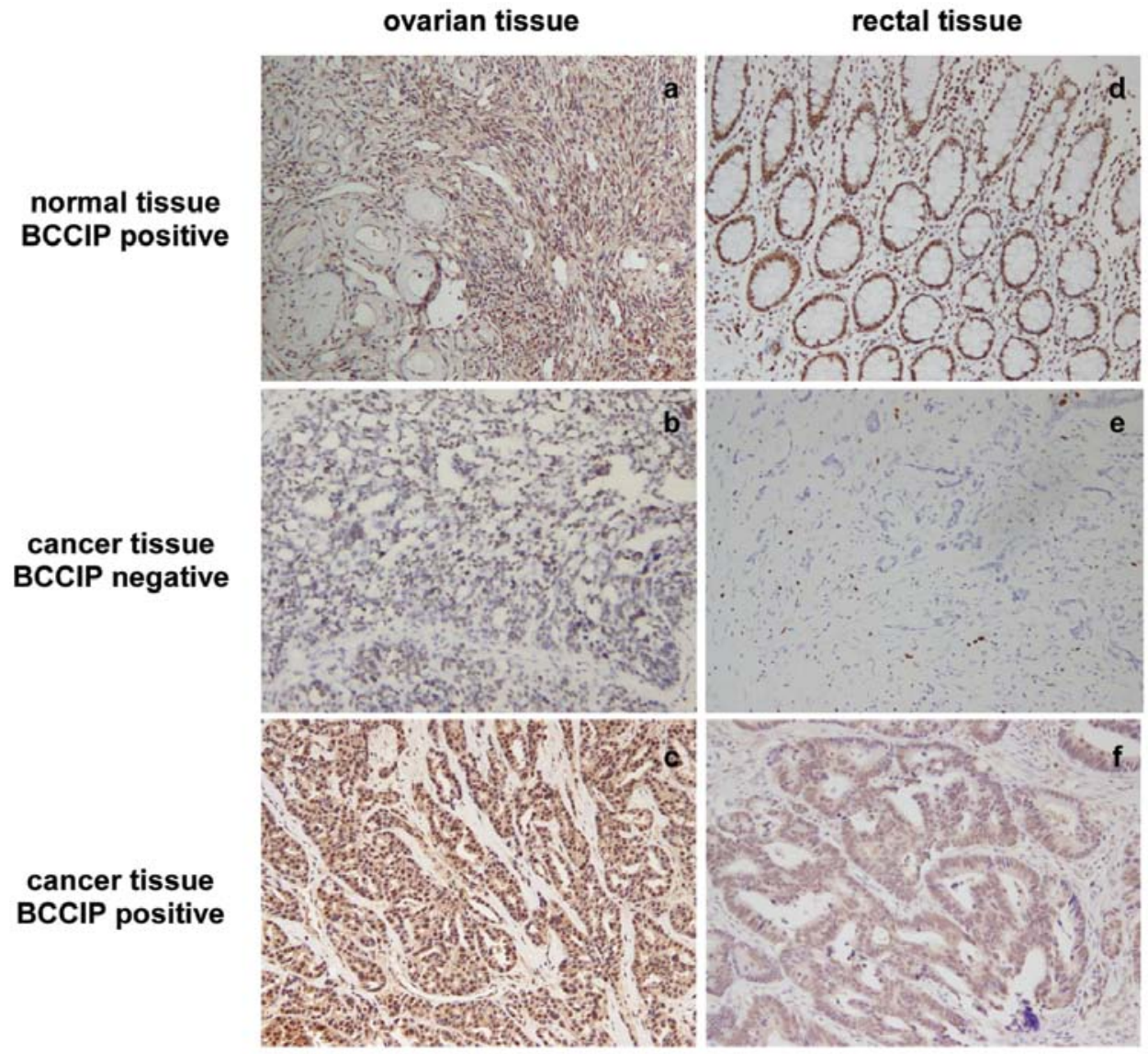

Figure 8. IHC staining for BCCIP in ovarian cancer and CRC tissues (x200). The top panel is representative of normal tissue (a and d). Negative (b and e) or positive (c and f) BCCIP expression in ovarian cancer and CRC. 
$(\mathrm{p}<0.001)$ compared with normal tissues. BCCIP expression in CRC tissues was decreased, but this was not statistically significant between cancer and normal tissues $(\mathrm{p}=0.0577)$.

Although the functions of BCCIP in tumor formation and progression are unclear, that its interaction with BRCA2 and p21 suggests a potential critical role in cancer pathogenesis. Genomic instability is a major driving force in tumor progression and tumor suppressor gene BRCA2 participates in the regulation of chromosomal stability, with respect to chromosome structure and number (26-28). BCCIP, as a BRCA2 and p21 interacting protein, co-localizes with BRCA2 on the chromatin fraction and contributes to BRCA2 and RAD51 nuclear focus formation (5). Furthermore, BCCIP is implicated in homologous recombination and cell cycle regulation $(9,29)$. These roles support the idea of BCCIP in the maintenance of genomic stability that may be involved in tumorigenesis. $\mathrm{BCCIP} \alpha$ protein was reduced in the 27 cancer cell lines in $3 / 9$ brain tumor cell lines, $3 / 7$ breast cancer cell lines and 2/4 endometrial tumor cell lines (3). In contrast, overexpression of BCCIP $\alpha$ moderately inhibits cell growth in certain brain and breast cancers (3), so BCCIP may be important for various types of tumor development. Liu et al (30) reported that BCCIP expression was not detectable in $\sim 45 \%$ of all astrocytic tumors and in $>60 \%$ of grade IV glioblastomas. Here, we found a significant ( $>2$-fold decreased) downregulation of BCCIP in 56\% (30/54) of ovarian cancer tissue samples, $70 \%$ (35/50) RCC tissues and 45\% (20/44) CRC tissues. A statistically significant reduction of BCCIP expression was detected in all tissue samples of serous, endometrioid, and mucinous carcinomas, and the greatest reduction of BCCIP was detected in pT3 serous carcinomas tumors $(\mathrm{p}<0.001)$. In addition, BCCIP was observed in RCC samples, data which support previous findings in 15 kidney tumor cases (3). The relationship between BCCIP expression and RCC clinicopathological features suggested that downregulation of BCCIP is strongly correlated with ccRCC. Also, low expression of BCCIP is closely related to Fuhrman tumor grading (Fig. 4B). BCCIP expression decreased in CRC tissues but this was not statistically significant $(\mathrm{p}=0.0577 ; \mathrm{n}=44)$. Only male $\mathrm{CRC}$ tissues $(\mathrm{p}<0.05)$ and CRC tissues $(\mathrm{p}<0.01)$ from pT4 tumors had a statistically significant difference in BBCIP. Western blot analysis and IHC revealed that BCCIP protein is also significantly reduced in ovarian cancer and RCC. These data, along with published literature confirm that BCCIP may be common in cancer tumors and may represent a novel biomarker for tumor diagnosis.

In conclusion, a significant reduction of BCCIP expression in ovarian cancer and RCC tissues compared with normal tissues was found. BCCIP expression in CRC tissues was decreased, but this was not statistically significant between cancer and normal tissues. Our data suggest a role for the $B C C I P$ in the pathogenesis of these cancers.

\section{Acknowledgements}

This study was supported by National Natural Science Foundation of China (31071131, Y.C.), and in part by the National Laboratory of Biomacromolecules, Institute of Biophysics, Chinese Academy of Sciences (2012kf04, J.J. and O5SY02110A, Y.C.).

\section{References}

1. Ono T, Kitaura H, Ugai H, Murata T, Yokoyama KK, Iguchi-Ariga SM and Ariga $\mathrm{H}$ : Tok-1, a novel p21 Cipl-binding protein that cooperatively enhances p21-dependent inhibitory activity toward CDK2 kinase. J Biol Chem 275: 31145-31154, 2000.

2. Liu J, Yuan Y, Huan J and Shen Z: Inhibition of breast and brain cancer cell growth by BCCIP $\alpha$, an evolutionarily conserved nuclear protein that interacts with BRCA2. Oncogene 20: 336-345, 2001.

3. Meng X, Liu J and Shen Z: Genomic structure of the human BCCIP gene and its expression in cancer. Gene 302: 139-146, 2003.

4. Fan J, Wray J, Meng X and Shen Z: BCCIP is required for the nuclear localization of the $\mathrm{p} 21$ protein. Cell Cycle 8: 3019-3024, 2009.

5. Lu H, Guo X, Meng X, Liu J, Allen C, Wray J, Nickoloff JA and Shen Z: The BRCA2-interacting protein BCCIP functions in RAD51 and BRCA2 focus formation and homologous recombinational repair. Mol Cell Biol 25: 1949-1957, 2005.

6. Meng X, Liu J and Shen Z: Inhibition of G1 to S cell cycle progression by BCCIP $\beta$. Cell Cycle 3: 343-348, 2004.

7. Meng X, Lu H and Shen Z: BCCIP functions through p53 to regulate the expression of $\mathrm{p} 21^{\text {Waf1/Cip1 }}$. Cell Cycle 3: 1457-1462, 2004.

8. Meng X, Fan J and Shen Z: Roles of BCCIP in chromosome stability and cytokinesis. Oncogene 26: 6253-6260, 2007.

9. Wray J, Liu J, Nickoloff JA and Shen Z: Distinct RAD51 associations with RAD52 and BCCIP in response to DNA damage and replication stress. Cancer Res 68: 2699-2707, 2008.

10. Lu H, Huang YY, Mehrotra S, Droz-Rosario R, Liu J, Bhaumik M, White E and Shen Z: Essential roles of BCCIP in mouse embryonic development and structural stability of chromosomes. PLoS Genet 7: e1002291, 2011.

11. Siegel R, Naishadham D and Jemal A: Cancer statistics. CA Cancer J Clin 62: 10-29, 2012.

12. Jemal A, Siegel E, Ward E, Murray T, Xu J and Thun MJ: Cancer statistics. CA Cancer J Clin 57: 43-66, 2007.

13. Sameer AS: Colorectal cancer: molecular mutations and polymorphisms. Front Oncol 3: 114, 2013.

14. Schwab LP, Peacock DL, Majumdar D, Ingels JF, Jensen LC, Smish KD, Cushing RC and Seagroves TN: Hypoxia-inducible factor $1 \alpha$ promotes primary tumor growth and tumor-initiating cell activity in breast cancer. Breast Cancer Res 14: R6, 2012.

15. McDonald PC, Winum JY, Supuran CT and Dedhar S: Recent developments in targeting carbonate anhydrase IX for cancer therapeutics. Oncotarget 3: 84-97, 2012.

16. Law AY and Wong CK: Stanniocalcin-2 is a HIF-1 target gene that promotes cell proliferation in hypoxia. Exp Cell Res 316: 466-476, 2010.

17. Choschzick M, Oosterwijk E, Müller V, Woelber L, Simon R, Moch $\mathrm{H}$ and Tennstedt P: Overexpression of carbonic anhydrase IX (CAIX) is an independent unfavorable prognostic marker in endometrioid ovarian cancer. Virchows Arch 459: 193-200, 2011.

18. Seeber LM, Horrée N, Vooijs MA, Heintz AP, van der Wall E, Verheijen RH and van Diest PJ: The role of hypoxia inducible factor-1 alpha in gynecological cancer. Crit Rev Oncol Hematol 78: 173-184, 2011.

19. Edge SB, Byrd DR, Compton CC, Fritz AG, Greene FL and Trotti A: AJCC Cancer Staging Manual. 7th edition. Springer, Chicago, IL, 2010.

20. Tavassoli FA and Devilee P (eds): Patholology and genetics. Tumors of the breast and female genital organs. In: World Health Organization Classification of Tumors. IARC Press, Lyon, 2003.

21. Gilks CB, Ionescu DN, Kalloger SE, Köbel M, Irving J, Clarke B, Santos J, Le N, Morravan V and Swenerton K: Tumor cell type can be reproducibly diagnosed and is of independent prognostic significance in patients with maximally debulked ovarian carcinoma. Hum Pathol 39: 1239-1251, 2008.

22. Mostofi FK (ed): Histological typing of kidney tumors. In: World Health Organization International Classification of Tumors. Springer-Verlag, New York, NY, 1998.

23. Fuhrman SA, Lasky LC and Limas C: Prognostic significance of morphologic parameters in renal cell carcinoma. Am J Surg Pathol 6: 655-663, 1982.

24. Merlo A: Genes and pathways driving glioblastomas in humans and murine disease models. Neurosurg Rev 26: 145-158, 2003. 
25. Ohgaki H, Dessen P, Jourde B, Horstmann S, Nishikawa T, Di Patre PL, Burkhard C, Schüler D, Probst-Hensch NM, Maiorka PC, Baeza N, Pisani P, Yonekawa Y, Yasargil MG, Lütolf UM and Kleihues P: Genetic pathways to glioblastoma: a population-based study. Cancer Res 64: 6892-6899, 2004.

26. Powell SN and Kachnic LA: Roles of BRCA1 and BRCA2 in homologous recombination, DNA replication fidelity and the cellular response to ionizing radiation. Oncogene 22: 5784-5791, 2003.

27. Daniels MJ, Wang Y, Lee M and Venkitaraman AR: Abnormal cytokinesis in cells deficient in the breast cancer susceptibility BRCA2. Science 306: 876-879, 2004.
28. Rudkin TM and Foulkes WD: BRCA2: breaks, mistakes and failed separations. Trends Mol Med 11: 145-148, 2005.

29. Lu H, Yue J, Meng X, Nickoloff JA and Shen Z: BCCIP regulates homologous recombination by distinct domains and suppresses spontaneous DNA damage. Necleic Acids Res 35: 7160-7170, 2007.

30. Liu J, Lu H, Ohgaki H, Merlo A and Shen Z: Alterations of BCCIP, a BRCA2 interacting protein, in astrocytomas. BMC Cancer 9: 268, 2009. 